\title{
Could hatha yoga be a health-related physical activity?
}

\author{
Małgorzata Grabara
}

Faculty of Health-Related Physical Activity, Department of Physical Education, Jerzy Kukuczka Academy of Physical Education, Katowice, Poland

\section{Summary}

The objectives of this review paper are (I) the analysis based on previous studies of whether hatha yoga exercises fulfil the recommendation for the level of physical activity recommended by the WHO and ACSM; (II) the recommendation for how to arrange weekly hatha yoga practice, which can be considered a health-related physical activity; and (III) the analysis of the benefits of a regular hatha yoga workout in view of scientific studies, in particular regard to the prevention of diseases of civilization and improvement in health-related physical fitness.

Based on previous studies, only dynamic Sun Salutations of yoga exercises (Suryanamaskar) are moderate-intensity physical activity, and therefore must be performed at least 5 days a week in $30 \mathrm{~min}$ duration or $150 \mathrm{~min}$ per week meet the recommendation. Hatha yoga meets the recommendations regarding types of exercise, because it includes poses improving muscular strength and endurance, flexibility, and balance. Dynamic sequences of Sun Salutation can be regarded as aerobic exercises. Regular hatha yoga training may be an intervention for the primary and secondary prevention of diseases of civilization. Yoga exercises were found to produce reductions in diastolic blood pressure; to improve cardiorespiratory system and metabolic parameters; to correct posture; to reduce back pain; to prevent obesity; to lower blood glucose level; to be beneficial for stress and depression; to relieve perceived pain; and to improve functional fitness and perceived quality of life. Hatha yoga also improves physical fitness, especially in regards to health-related fitness.

In the context of the recommendation and reported benefits, hatha yoga is the health-related physical activity.

\section{Key words: Hatha yoga - Physical fitness - Diseases of civilization - Benefits of yoga - Health-related physical activity}

\section{Background}

Physical activity (PA) is a duty of modern man. PA is interrelated with health and quality of life. Research findings clearly show of the importance of PA in the prevention and treatment of the diseases of civilization [48]. This mainly applies to cardiorespiratory diseases, metabolic diseases, and musculoskeletal disorders including osteoporosis, back pain and arthritis $[5,7,23$, $24,31,39]$. The aetiology of these diseases is in fact identified with the wrong lifestyle of the present generations, especially with low PA (hypokinesia) and improper nutrition [9].

Hatha yoga (physical exercises of yoga) is a form of recreational physical activity. It is a part of yoga as an Indian philosophical system integrating the mind and the body through physical postures. Yoga comprises the lifestyle, meditation, pranayama and yoga postures (asanas).
Over the years, yoga has undergone many transformations and has changed its reception. Currently, yoga is considered one of fitness forms defined as forms of body and mind. Hatha yoga includes dozens of different positions and their variations called 'asanas'. Hatha yoga is based on slow or fast and smooth entry into, duration in, and exit from the pose. There are many kinds of hatha yoga, including more dynamic sequences of poses combined with the breath. Regular hatha yoga practice has many health benefits.

The objectives of this paper are (I) the analysis based on previous studies of whether exercises of hatha yoga fulfil the recommendation for the level of physical activity recommended by various institutions (WHO, ACSM); (II) the recommendation for how to arrange weekly hatha yoga practice which can be considered a health-related physical activity in the context of the ACSM or WHO recommendation; and (III) the analysis of the benefits of a regular hatha yoga workout in view of scientific studies, 
in particular regards to the prevention of diseases of civilization and improvement in health-related physical fitness.

\section{Recommendations for health-related physical activity}

To consider undertaken PA as health-related, it should feature appropriate qualitative and quantitative parameters $[22,48]$ comprising intensity, frequency, volume and type of physical activity.

The World Health Organization [48] makes the following recommendations for adults aged 18-64 yr: do at least 150 min of moderate-intensity aerobic PA throughout the week or do at least $75 \mathrm{~min}$ of vigorous-intensity aerobic PA throughout the week or an equivalent combination of moderate - and vigorous-intensity activity. Aerobic activity should be performed in bouts of at least $10 \mathrm{~min}$ duration. On a scale relative to an individual's personal capacity, moderate-intensity PA is usually a 5 or 6 on a scale of $0-10$, and vigorous-intensity PA is a 7 or 8 on the same scale. Furthermore, muscle-strengthening activities should be done involving major muscle groups on 2 or more days a week [48].

According to the American College of Sports Medicine (ACSM) and the American Heart Association (AHA) recommendations to promote and maintain health, all healthy adults aged 18 to $65 \mathrm{yr}$ need moderate-intensity aerobic (endurance) PA for minimum of 30 min on 5 days each week or vigorous-intensity aerobic PA for a minimum of $20 \mathrm{~min}$ on 3 days each week. Combinations of moderate - and vigorous-intensity PA can be performed to meet this recommendation [22]. All energy expenditure (EE) related to PA should be above 500-1000 METs/min per week [11]. Just as with the WHO's recommendation, PA should be performed in bouts of at least 10 min duration. Moreover, every adult should perform activities that maintain or increase muscular strength and endurance a minimum of 2 days each week. It is recommended that individuals should perform 8-10 exercises using the major muscle groups on two or more nonconsecutive days each week [22]. It is also recommended that they perform activities to increase flexibility, balance, agility and coordination [11]. Activities that increase flexibility should be performed using the major muscle and holding the position at least 60 seconds, a minimum of 2-3 days each week [11]. Stretching exercises should be included in the warm up and cool down [33].

\section{Does hatha yoga fulfil the recommendations?}

Physical yoga (hatha yoga) includes the exercises in standing poses, sitting poses, laying poses, supine and prone poses, poses involving hand support, balance poses and more. There are mostly static positions, which the practitioner is lasting from over a dozen seconds to several minutes. Depending on the complexity of the positions, dynamic transitions, and the efficiency of the practitioner or the extent of his/her advancement, the performance of the individual poses carries a different $\mathrm{EE}$ and is associated with various heart rate training.

Clay et al. (2005), in their study including 26 male and female students aged 19-26 yr (mean 23), reported that during the $30 \mathrm{~min}$ yoga workout, maximal oxygen consumption, EE [METS, $\mathrm{kcal} / \mathrm{min}$ ], heart rate training and percentage of $\mathrm{HR}_{\text {max }}$ of the studied subjects are significantly lower than during marching at a speed of $5.6 \mathrm{~km} / \mathrm{h}$ (defined as adequate exercise to improve cardiorespiratory fitness) [8]. The authors found that hatha yoga is a training of low intensity and therefore does not meet the ACSM recommendation for levels of PA for improving or maintain cardiorespiratory fitness. However, the intensity of the Sun Salutation (Suryanamaskar) authors determined at the level of 3.74 METs and $67 \%$ of $\mathrm{HR}_{\max }$ [8], which places the intensity of the exercises at a moderate level, thus fulfilling the ACSM recommendations.

Ray et al. (2011), in their study involving 20 men aged $27.4 \pm 3.45 \mathrm{yr}$ (yoga instructors practising yoga 6-10 yr), stated the intensity at a level that does not exceed 1-2 METs and up to $30 \% \mathrm{VO}_{2 \max }$ [35]. It should be noted that the subjects performed only seated positions, lying and reversed, and the position of the cobra and bow, and the highest-intensity hatha yoga exercise sequences were recorded for Suryanamaskar and standing positions $[8,20,35]$.

The results of the 2007 Hagins et al. study involving 20 intermediate - to advanced-level yoga practitioners (age $31 \pm 8 \mathrm{yr}$ ) showed that the EE of the entire yoga session represented a low level of PA, comparable to marching at a speed of $3.2 \mathrm{~km} / \mathrm{h}$, and did not meet the recommendation regarding the level of PA beneficial for improving cardiorespiratory fitness, determined at least 3 METs [20, 22]. The mean value of energy expenditure of yoga averaged across the entire session was 2.5 METs, and an average training HR was 93.2 BPM, which accounted for $49 \%$ of $\mathrm{HR}_{\max }$ and also was lower than the training HR recommended by the ACSM, amounting to $55 \%$ of $\mathrm{HR}_{\max }$ $[20,33]$. The highest EE (2.9 METs) and HR training (103.5 BPM) was recorded during Suryanamaskar [20].

In the Bhutkar et al. study, the subjective feeling of effort intensity in Suryanamaskar, based on the Borg scale, when evaluated by men, corresponded to a $50 \% \mathrm{VO}_{2 \max }$ and, when evaluated by women, corresponded to a $75 \%$ $\mathrm{VO}_{2 \max }[3]$. Thus, yoga training with Suryanamaskar that exceeds the minimum bout of $10 \mathrm{~min}$ can contribute some portion of the recommended PA to improve cardiorespiratory endurance in unfit or sedentary individuals [20].

Based on the compendium of PA developed by Ainsworth et al. (2011), the EE of hatha yoga is 2.5 METs, the EE of power yoga (the most dynamic hatha yoga) is 4 METs and the EE of Suryanamaskar is 3.3 METs [1].

Besides adequate intensity of PA, the type of exercise (aerobic, strength, flexibility and balance) is 
also important. Hatha yoga includes poses shaping muscle strength and endurance (e.g., asanas support balance on one's hands, standing asanas), poses using one's own body weight, poses shaping balance, and poses shaping flexibility. Furthermore, the dynamic transition from one position to another shapes agility and coordination, as well as the balance. The dynamic performing of Suryanamaskar we can regard as aerobic exercises. Thus, hatha yoga training could meet the recommendations regarding the type of exercises. However, much depends on individual fitness of the practitioner, his/her advancement, and primarily on the chosen postures during yoga training. For fit individuals only dynamic Suryanamaskar or power yoga may be appropriate, recommended as a health prevention intensity. Proper selection of exercises for yoga training, its duration and frequency, and optional supplementation with other forms of PA are crucial to maintain and improve physical fitness.

\section{Weekly yoga workout (poses, intensity, duration and frequency)}

In order to maintain a moderate-intensity exercise, you must perform Suryanamaskar exercises and dynamic transitions during the standing postures sequence, which can also be included into the sequence of Suryanamaskar. The duration of this part of the yoga training should be at least $30 \mathrm{~min}$. The moderate intensity of the exercise can also be achieved during the balancing on the hands sequences, but those poses require some skill and advancement of the practitioner.

The frequency of yoga training, because of its moderate or low intensity, should be at least 5 times a week for $60-90 \mathrm{~min}$ duration, if a practitioner is not involved in other forms of moderate - or vigorous-intensity PA. In the case of involving different, mainly aerobic or strength $\mathrm{PA}$, the hatha yoga workout can be treated as stretching or preventive exercises for back pain. Then, the practitioner should focus on poses shaping flexibility, poses elongating the spine, twisting poses, reversed poses and relaxation. In that case, hatha yoga training should be 2 to 3 times a week, for about 45-90 min. However, if we treat hatha yoga only as stretching exercises, asanas shaping flexibility should be performed even daily or at least 3 times a week about 10-15 min, and we must hold the pose for 30-60 seconds.

Hatha yoga training should include the following groups of poses (the names of poses are given also in Sanskrit):

- pose shaping proper posture, i.e., Mountain pose (Tādāsana);

- standing poses with the body workout in the sagittal plane, e.g., Chair Pose (Utkatāsana), Standing Forward Bend (Uttānāsana), Warrior I, III (Vìrabhadrāsana I, III);
- standing poses with the body workout in the frontal plane, e.g., Extended Triangle Pose (Utthita Trikonāsana), Extended Side Angle Pose (Utthita pārśva koṇāsana), Half Moon (Ardha Candrāsana), Gate Pose (Parighāsana);

- standing poses with the body workout in the transverse plane, e.g., Revolved Triangle (Parivrtta Trikonāsana), Revolved Side Angle Pose (Parivrtta Pārśvakonāsana);

- arm support poses, e.g., Cat pose (bidalasana), Plank (Utthita Chaturanga Dandāsana), Downward Facing Dog (Adho Mukha Śvānāsana);

- balance poses - standing on one leg, e.g., Eagle Pose (Garudāsana), Tree Pose (Vrkșāsana), King of the Dancers Pose (Națarājāsana), Extended Hand-Toe Pose (Utthita Hasta Pādāngușthāsana);

- strengthening poses including the core muscles, e.g., Locust pose (Śalabhāsana), Side Plank (Vasisthāsana), Full Boat pose (Paripūrnanāvāsana); upper and lower limbs muscles, e.g., Warrior II (Vìrabhadrāsana II), Upward Plank (Purvottanāsana), Low Plank (Caturanga Daṇ̂̄āsana);

- poses that extend chest muscles, e.g., camel pose (Ustrāsana), upward bow pose (Urdhva Danurāsana); shoulder girdle muscles, e.g., Cow Face Pose (Gomukhāsana); hamstrings, e.g., seated forward bend (Paścimottānāsana); head-to-knee pose (Jānu Sirșāsana); hip flexors, e.g., Crescent Moon pose (Anjaneyāsana), One-Legged King Pigeon pose (Eka Pāda Rājakapotāsana), triceps surae muscles, e.g., Garland pose (Malāsana), Warrior I (Vīrabhadrāsana I); back muscles, especially in the lumbar region, e.g., Child's pose (balasana), Belly twist pose (Jathara Parivartāsana);

- prone poses, e.g., Upward Facing Dog (Urdhva Mukha Śvānāsana), Bow (Dhanurāsana), Cobra (Bhujangasāna);

- sitting poses, also poses with body workout in sagittal and transversal planes, e.g., Accomplished Pose (Siddhasana), Bound Angle Pose (Badha Konāsana), Wide Angle Seated Forward Bend (Upavistha Konāsana), Half Load of the Fishes Pose (Ardha Matsyendrāsana), Marichi's pose (Marichyāsana);

- lying poses, e.g., Apana pose (Apanāsana), SideReclining Leg Lift (Anantāsana), Reclining Bound Angle Pose (Supta Baddha Konasana), Crocodile (Makarāsana);

- reversed poses - only if there are no contraindications, e.g., Headstand (Sirsāsana), Plow Pose (Halāsana), Supported Shoulder Stand Pose (Salamba Sarvangāsana);

- relaxation pose, e.g., Corpse pose (Śavāsana) [16].

Most of the hatha yoga poses meet more than one objective, e.g., upward bow pose (Urdhva Danurāsana), 
is a prone pose, pose extending chest muscles, and pose strengthening upper and lower limb muscles.

According to the methods of conducting fitness classes, hatha yoga training consists of 3 parts:

- the initial, which contains instructions for participants, questions about any medical conditions precluding the exercise of some asanas (in the case of group activities), and performance of the Mountain pose with special attention to the positions of each parts of the body and elongation of the spine;

- the main part, which includes Suryanamaskar as a dynamic warm up; standing asanas in sagittal, frontal and transverse planes; balance poses; muscle-strengthening poses; muscle-extending poses; prone poses; and sitting poses;

- the end part intended for lying poses, reversed poses and relaxing poses.

Of course, hatha yoga training must be tailored to the age, health, physical fitness and the ability of practitioners. Therefore, exercises, dynamic moves, jumps, numerous arm support poses or reversed poses will not be suited for everyone.

\section{Health benefits of regular yoga training in the context of civilization diseases prevention}

Regular practice of hatha yoga may be the important intervention for the primary and secondary prevention of diseases of civilization. Based on the results of previous studies, yoga exercises were found, among other things, to produce reductions in diastolic blood pressure; to improve cardiorespiratory system $[21,30,34,42]$, respiratory system $[4,49]$ and metabolic parameters [40]; to correct posture $[13,14,15,19]$; to reduce back pain $[26,46]$; to help in the management of those with urological disorders [36]; to prevent obesity [29]; to lower blood glucose level and to contribute to the better control of type II diabetes [25, 37]. Yoga has also been found to be beneficial for stress and depression [41, 47]. The beneficial effect of hatha yoga was also found in women with osteoporosis. This study revealed that regular yoga practice could relieve perceived pain, improve functional fitness and improve perceived quality of life [50].

Devasena i Narhare (2011), in their study involving 20 women and 30 men aged about $40 \mathrm{yr}$, reported a significant decrease in $\mathrm{HR}_{\text {rest }}$ as well as systolic and diastolic blood pressure as a result of 6-month hatha yoga practice including breathing and concentrating exercises [10]. Murugesan et al. (2000) also proved that as a result of 11-week hatha yoga training performed 6 times weekly for $60 \mathrm{~min}$, there was a decrease in systolic and diastolic blood pressure [30]. In the context of the studies mentioned above, hatha yoga can be a form of physical activity recommended for, among others, the prevention of hypertension, especially for individuals in middle and old age.
Previous studies also found that despite low energy expenditure, hatha yoga can be important in the primary and secondary prevention of cardiorespiratory disease and prevention of obesity [21, 40, 42]. Performing more difficult and more dynamic poses for 90 min causes expenditure of $250 \mathrm{kcal}$, which is appropriate in the management of body weight [8].

Hatha yoga exercises shape the habit of proper posture, enhance postural muscles and improve flexibility. Elongation of the spine, typical for hatha yoga poses, reduces overloads of passive apparatus of motion, thus reducing back pain. Assessment of the shape of the anterior-posterior spinal curvatures among people over $55 \mathrm{yr}$ old showed a reduction of excessive thoracic kyphosis and lumbar lordosis as a result of the weekly 90 -minute hatha yoga training for 8 months [13].

\section{Effects of hatha yoga training on the health-related aspects of physical fitness}

Previous studies focused on the effects of hatha yoga on physical fitness assessed, among others, the effects on flexibility $[12,17,18,27,44]$, muscle strength and endurance $[3,27,44]$, cardiorespiratory fitness $[2,27,34]$, balance $[38,45]$, reaction time [28] and body composition $[2,3,40]$.

Ramos-Jiménez et al. (2009) proved in their study that a 90-minute program of intensive hatha yoga improves cardiorespiratory fitness in women aged $43.2 \pm 3.1$ and $62.2 \pm 5.9$ practising hatha yoga [34]. Assessment of the effects of 60-minute Suryanamaskar performed 6 days a week showed a significant increase in muscle strength and endurance, especially in the upper body, as well as weight loss and BMI reduction in men and women aged 18-20 yr [3].

Madanmohan et al. (1992), in their study involving healthy men aged 18-21 yr attending yoga classes 6 days a week for 12 weeks in 30 min duration, revealed a significant reduction in reaction time, which could be due to an enhanced processing ability of the central nervous system [28]. There was also an increase in maximum expiratory and inspiratory pressure, breath holding time (by improving the strength of expiratory and inspiratory muscles), and hand grip [28].

Tran et al., in their study of 11 women and 3 men aged 18-27 yr who attended 32 classes of physical yoga combined with $10 \mathrm{~min}$ of breathing exercises and $10 \mathrm{~min}$ of relaxation (90 min, 4 times a week for 8 weeks), exhibited improvement in the muscular strength of elbow flexors and extensors and knee extensors; improvement in the muscular endurance of knee flexors; improvement in flexibility of the ankle and shoulder joints; enhancement of the range of extension and flexion of the trunk; and increase in maximal oxygen uptake [44]. In the same study authors did not find the significant changes in body composition, 
expired ventilation, $\mathrm{HR}_{\max }$, or pulmonary function (FVC, FEV). Based on percentage changes, the most improvement was found in flexibility [44].

$\mathrm{Lau}$ et al. revealed a significant increase in $\mathrm{VO}_{2 \max }$, muscle strength and endurance, and flexibility in the lower back and hamstrings in groups of men and women with a mean age of $52 \pm 7.5$ who practised yoga for 12-weeks (60 min per week) compared to control groups. In a group of women, the authors also noticed significant decrease in $\mathrm{HR}_{\text {rest }}[27]$.

Grabara and Szopa (2015) found an increase in flexibility of the spine and hamstrings in 56 women aged 50-79 yr who were attending yoga classes $90 \mathrm{~min}$ per week for 20 weeks [17].

Bera and Rajapurkar (1993) showed significantly lower body fat, the improvement of bone density and cardiorespiratory fitness in boys aged $12-15 \mathrm{yr}$ practising yoga (for $1 \mathrm{yr}, 3$ days a week for 45 min duration) compared to sedentary individuals [2].

Ülger and Yağlı (2011) found the significant improvement of balance in women with musculoskeletal disorders aged 30-45 yr who practised hatha yoga 2 days a week for 4 weeks [45]. Nick et al. also indicated an improvement of balance and decreasing fear of falling in people aged 60-74 yr after hatha yoga training 2 days a week for 8 weeks [32].

It is worth emphasizing that hatha yoga is a very good activity for the elderly. There is the special program of hatha yoga called 'silver yoga exercises', and it is recommended for older people in order to improve their physical fitness and promote health [6]. The results of a study involving individuals over $60 \mathrm{yr}$ proved a significant increase of joint mobility and improvement of functional fitness and perceived quality of life due hatha yoga training 2 days per week for $60 \mathrm{~min}$ for a period of 14 weeks [12]. The results of another study confirmed an increase of flexibility, endurance of lower limb muscles, and reduction of systolic blood pressure in elderly people practising yoga [6].

\section{Conclusions}

The objective of this paper was, among others, the analysis of whether hatha yoga meets the recommendation for the level of physical activity recommended by various institutions. Based on the previous studies it could be concluded that only dynamic Sun Salutations (Suryanamaskar) are moderate-intensity physical activity, when performed at least 5 days a week in $30 \mathrm{~min}$ duration or $150 \mathrm{~min}$ per week to meet the recommendations. Dynamic varieties of Suryanamaskar can be regarded as aerobic exercises due to the documented benefits of yoga improving cardiorespiratory fitness. Hatha yoga also meets the recommendations regarding type of exercise, because it includes poses improving muscular strength and endurance, flexibility, and balance.

Regular hatha yoga training may be an intervention for the primary and secondary prevention of diseases of civilization, which has been confirmed in previous studies. Hatha yoga also improves physical fitness, especially in regards to health-related fitness.

In the context of the recommendation and reported benefits hatha yoga is the health-related physical activity.

\section{References}

1. Ainsworth, B., W. Haskell, S. Herrmann, N. Meckes, D. Jr Bassett, C. Tudor-Locke et al. (2011) Compendium of Physical Activities: a second update of codes and MET values. Med. Sci. Sports Exerc., 43(8): 1575-1581.

2. Bera T., M. Rajapurkar (1993) Body composition, cardiovascular endurance and anaerobic power of yogic practicioner. Indian J. Physiol. Pharmacol., 37(3): 225-228.

3. Bhutkar M., P. Bhutkar, G. Taware, A. Surdi (2011) How effective is sun salutation in improving muscle strength, general body endurance and body composition? Asian J. Sports Med., 2(4): 259-266.

4. Birkel D., L. Edgren (2000) Hatha yoga: Improved vital capacityof college students. Altern. Ther. Health Med., 6(6): 55-63.

5. Bouchard C., J. Depres, A.Tremblay (1993) Exercise and obesity. Obes. Res., 1: 133-147.

6. Chen K., M. Chen, S. Hong, H. Chao, H. Lin, C. Li (2008) Physical fitness of older adults in senior activity centres after 24-week silver yoga exercises. J. Clinic. Nurs., 17: 2634-2646.

7. Cicero A., S. D'Addato, F. Santi, A. Ferroni, C. Borghi (2012) Leisure-time physical activity and cardiovascular disease mortality: the Brisighella Heart Study. J. Cardiovasc. Med., 13(9): 559-564.

8. Clay C., L. Lloyd, J. Walker, K. Sharp, R. Pankey (2005) The metabolic cost of hatha yoga. J. Strength Condition. Res., 19(3): 604-610.

9. Corbin C.B., G. Welk, W.R. Corbin, K. Welk (2001) Concepts of fitness and wellness. McGraw-Hill, Boston.

10. Devasena I., P. Narhare (2011) Effect of yoga on heart rate and blood pressure and its clinical significance. Int. J. Biol. Med. Res. 2(3): 750-753.

11. Garber C., B. Blissmer, M. Deschenes, B. Franklin, M. Lamonte, I. Lee, et al. (2011) American College of Sports Medicine position stand. Quantity and quality of exercise for developing and maintaining cardiorespiratory, musculoskeletal, and neuromotor fitness in apparently healthy adults: guidance for prescribing exercise. Med. Sci. Sports Exerc., 43(7): 1334-1359.

12. Gonçalves L., R. de Souza Valea, N. Barata, R. Varejão, E. Dantas (2011) Flexibility, functional autonomy and 
quality of life (QoL) in elderly yoga practitioners. Arch. Gerontol. Geriatr., 53: 158-162.

13. Grabara M. (2013) Effect of 8-moths yoga training on shaping the spine in people over 55. Biomed. Hum. Kinet., 5: 59-64.

14. Grabara M., J. Szopa (2011) Effects of hatha yoga on the shaping of the antero-posterior curvature of the spine. Hum. Mov., 12(3): 259-263.

15. Grabara M., J. Szopa (2011) Habitual body posture and mountain position of people practising yoga. Biol. Sport, 28: $51-54$.

16. Grabara M., J. Szopa (2013) Asany jogi dla współczesnego człowieka (ed. II) AWF, Katowice.

17. Grabara M., J. Szopa (2015) Effects of hatha yoga exercises on spine flexibility in women over 50 years old. $J$. Phys. Ther. Sci., 27(2): 361-365.

18. Grabara M., J. Szopa, D. Grabara (2011) Flexibility of the spine and selected joints in women practising hatha yoga. Polish J. Sport Med., 27(1); 61-73.

19. Greendale G., M. Huang, A. Karlamangla, L. Seeger, S. Crawford (2009) Yoga decreases kyphosis in senior women and men with adult-onset hyperkyphosis: results of a randomized controlled trial. J. Am. Geriatr. Society, 57(9): 1569-1579.

20. Hagins M., W. Moore, A. Rundle (2007) Does practicing hatha yoga satisfy recommendations for intensity of physical activity which improves and maintains health and cardiovascular fitness? BMC Complement. Altern. Med., 7: 40.

21. Hartley L., M. Dyakova, J. Holmes, A. Clarke, M. Lee, E. Ernst, K. Rees (2014) Yoga for the primary prevention ofcardiovascular disease. Cochrane Db Syst. Rev., 5: CD010072.

22. Haskell W., I. Lee, R. Pate, K. Powell, S. Blair, B. Franklin et al. (2007) Physical activity and public health: updated recommendation for adults from the American College of Sports Medicine and the American Heart Association. Medicine and Science. Circulation, 116(9): 1081-1093.

23. Helmrich S., D. Ragland, R. Leung, R. Paffenberg (1991). Physical activity and reduced occurrence of non-insulindependent diabetes mellitus. New Engl. J. Med., 325(3): 147-152.

24. Hildebrandt V., P. Bongers, J. Dul, F. Van Dijk, H. Kemper (2000) The relationship between leisure time, physical activities and musculoskeletal symptoms and disability in worker populations. Int. Arch. Occup. Environ. Health, 73(8): 507-518.

25. Innes K., H. Vincent (2007) The Influence of Yoga-Based Programs on Risk Profiles in Adults with Type 2 Diabetes Mellitus: A Systematic Review. Evidence-Based Complement. Altern. Med., 4(4): 469-486.

26. Kim S., W. Min, J. Kim, B. Lee (2014) The effects of VR-based Wii Fit Yoga on physical function in middle-aged female LBP patients. J. Phys. Ther. Sci., 26: 549-552.

27. Lau C., R. Yu, J. Woo (2015) Effects of a 12-week hatha yoga intervention on cardiorespiratory endurance, muscular strength and Endurance, and flexibility in Hong Kong Chinese adults: a controlled clinical trial. EvidenceBased Complement. Altern. Med., ID: 958727.

28. Madanmohan T.D., B. Balakumar, T. Nambinarayanan, S. Thakur, N. Krishnamurthy, A. Chandrabose (1992) Effect of yoga training on reaction time, respiratory endurance and muscle strength. Indian J. Physiol. Pharmacol., 36(4): 229-232.

29. Moliver N., E. Mika, M. Chartrand, S. Burrus, R. Haussmann, S. Khalsa (2011) Increased Hatha yoga experience predicts lower body mass index and reduced medication use in women over 45 years. Int. J. Yoga, 4(2): 77-86.

30. Murugesan R., N. Govindarajulu, T. Bera (2000) Effect of selected yogic practices on the management of hypertension. Indian J. Physiol. Pharmacol., 44(2): 207-210.

31. Nguyen T., P. Sambrook, J. Eisman (1998) Bone loss, physical activity, and weight change in elderly women: the dubbo osteoporosis epidemiology study. J. Bone Miner. Res., 13(9): 1458-1467.

32. Nick N., P. Petramfar, F. Ghodsbin, S. Keshavarzi, I. Jahanbin (2015) The effect of yoga on balance and fear of falling in older adults. $P M \& R$ : the Journal of Injury, Function, and Rehabilitation: S1934-1482.

33. Pollock M., G. Gaesser, J. Butcher, J. Després, R. Dishman, B. Franklin, C. Garber (1998) American College of Sports Medicine Position Stand. The recommended quantity and quality of exercise for developing and maintaining cardiorespiratory and muscular fitness, and flexibility in healthy adults. Med. Sci. Sports Exerc., 30(6): 975-991.

34. Ramos-Jiménez A., R. Hernández-Torres, A. WallMedrano, M. Muñoz-Daw, P. Torres-Durán, M. JuárezOropeza (2009) Cardiovascular and metabolic effects of intensive Hatha Yoga training in middle-aged and older women from northern Mexico. Int. Yoga J., 2(2): 49-54.

35. Ray U., A. Pathak, O. Tomer (2011) Hatha yoga practices: energy expenditure, respiratory changes and intensity of exercise. Evidence-Based Complement. Altern. Med., ID: 241294: 1-12.

36. Ripoll E., D. Mahowald (2002) Hatha Yoga therapy management of urologic disorders. World J. Urol., 20(5): 306-309.

37. Sahay B. (2007) Role of Yoga in Diabetes. J. Assiociat. Phys. India, 55: 121-126.

38. Schmid A., M. Van Puymbroeck, D. Koceja (2010) Effect of a 12-week yoga intervention on fear of falling and balance in older adults: a pilot study. Arch. Phys. Med. Rehabil., 91(4): 576-583.

39. Schnohr P., H. Scharling, J. Jensen (2003) Changes in leisure-time physical activity and risk of death: An 
observational study of 7,000 men and women. Am. J. Epidemiol., 158(7): 639-44.

40. Seo D., S. Lee, A. Figueroa, H. Kim, Y. Baek, Y. Kwak et al. (2012) Yoga training improves metabolic parameters in obese boys. Korean J. Physiol. Pharmacol., 16: 175-180.

41. Shapiro D., I. Cook, D. Davydov, C. Ottaviani, A. Leuchter, M. Abrams (2007) Yoga as a complementary treatment of depression: effects of traits and moods on treatment outcome. Evidence-Based Complement. Altern. Med., 4(4): 493-502.

42. Sovová E., V. Cajka, D. Pastucha, J. Malincíková, L. Radová, M. Sovová (2015) Positive effect of yoga on cardiorespiratory fitness: A pilot study. Int. Yoga J., 8: 134-138.

43. Tiedemann A., S. O’Rourke, R. Sesto, C. Sherrington (2013) A 12-week Iyengar yoga program improved balance and mobiliy in older community-dwelling people: a pilot ramdomized controlled trial. J. Gerontol. Biol. Sci. Med. Sci., DOI: 10.1093/gerona/glt087.

44. Tran M., R. Holly, J. Lashbrook, E. Amsterdam (2001) Effects of hatha yoga practice on the health-related aspects of physical fitness. Prev. Cardiol., 4: 165-170.

45. Ülger Ö., N. Yağlı (2011) Effects of yoga on balance and gait properties in women with musculoskeletal problems: A pilot study. Complement. Ther. Clin. Pract., 17(1): 13-15.
46. Williams K., C. Abildso, L. Steinberg, E. Doyle, B. Epstein, D. Smith et al. (2009) Evaluation of the effectiveness and efficacy of Iyengar yoga therapy on chronic low back pain. Spine, 34(19): 2066-2076.

47. Woolery A., H. Myers, B. Sternlieb, L. Zeltzer (2004) A yoga intervention for young adults with elevated symptoms of depression. Altern. Ther. Health M., 10(2): 60-63.

48. Word Health Organization. Global Recommendations on Physical Activity for Health. (2010). Geneve. http:// whqlibdoc.who.int/publications/2010/9789241599979_ eng.pdf.

49. Yadav R., S. Das (2001) Effect of yogic practice on pulmonary functions In young females. Indian J. Physiol. Pharmacol., 45(4): 493-496.

50. Yağlı N., Ö. Ülge (2012) Effects of yoga on the quality of life and mobility in geriatric patients with osteoporosis. J. Yoga Phys. Ther., 2.

\section{Received 07.01.2016 \\ Accepted 01.02.2016}

(C) University of Physical Education, Warsaw, Poland 